\title{
Double Helix
}

National Human Genome Research Institute (NHGRI)

\section{Source}

National Human Genome Research Institute (NHGRI). Double Helix.

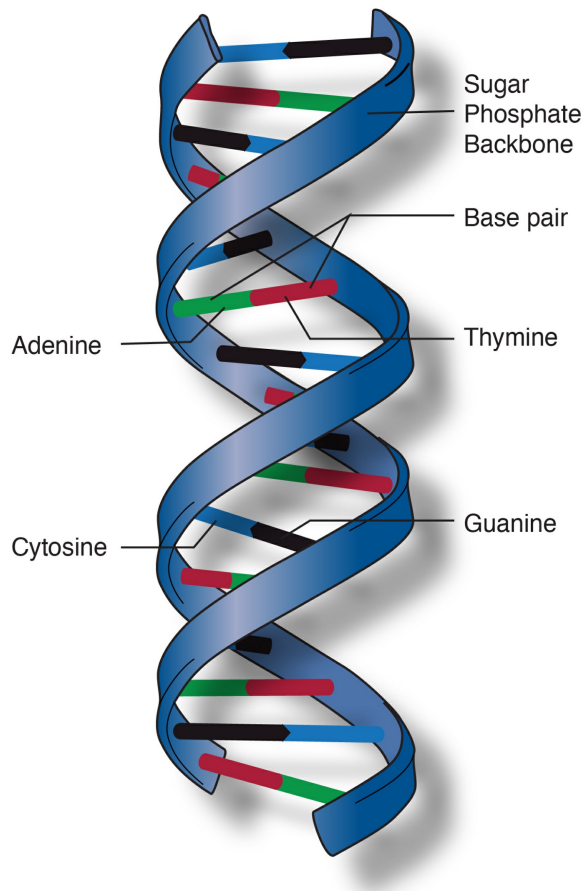

Double helix is the description of the structure of a DNA molecule. A DNA molecule consists of two strands that wind around each other like a twisted ladder. Each strand has a backbone made of alternating groups of sugar (deoxyribose) and phosphate groups. Attached to each sugar is one of four bases: adenine $(A)$, cytosine (C), guanine $(G)$, or thymine $(T)$. The two strands are held together by bonds between the bases, adenine forming a base pair with thymine, and cytosine forming a base pair with guanine. 